Pesq. Vet. Bras. 36(12):1215-1220, dezembro 2016 DOI: $10.1590 / \mathrm{S} 0100-736 \mathrm{X} 2016001200013$

\title{
Dimorfismo sexual e estrutura perineal em Coendou prehensilis (Ouriço-cacheiro) $^{1}$
}

\author{
Fabio Sergio Cury ${ }^{2 *}$ e Carlos Eduardo Ambrósio ${ }^{3}$
}

\begin{abstract}
Cury F.S. \& Ambrósio C.E. 2016. [Sexual dimorphism and perineal structure in Coendou prehensilis (Prehensile-tailed porcupine).] Dimorfismo sexual e estrutura perineal em Coendou prehensilis (Ouriço-cacheiro). Pesquisa Veterinária Brasileira 36(12):1215-1220. Departamento de Medicina Veterinária, Faculdade de Zootecnia e Engenharia de Alimentos, Universidade de São Paulo, Av. Duque de Caxias Norte, Pirassununga, SP 13635-000, Brazil. E-mail: fcury@usp.br

Coendou prehensilis is a mammal that belongs to the Rodentia order, which consists of five suborders: Sciuromorfos, to which the squirrels belongs; Castorimorfos where we have the beavers; Myomorfos, which include the mice; Anomaluromorfos, Hare jumper, and Hystricomorfos, where we have the capybara. We used the porcupine clerk in the research (Coendou prehensilis), one male and one female, both adults. These animals were transferred to the Laboratory of Anatomy, Department of Veterinary Medicine, Faculty of Animal Science and Food Engineering, University of São Paulo (FZEA/USP), originating from roadaccidents in Pirassununga, SP (Registration n. 43274-1 SISBIO). The animals were fixed with $10 \%$ formaldehyde and dissected in the perineum region. The results showed that the only feature which allows us to differentiate males from females is the space between anus and the genitals of the animals; the male has a larger space than the female. The perineum is an extra cavity region with lozenge definition, and this definition is formed by interpubic bones, the pubic and processes of the pubic and ischium. The male Coendou prehensilis perineum consists of five major muscles, three arranged on the urogenital diaphragm surface (ischiocavernosus muscles, M. bulbocavernosus and Mm. bulboesponjosos) and two in the pelvic diaphragm (M. levator ani and M. penis retractor). The female's perineum is composed by ischiocavernosus, bulbospongiosus, levator ani and external anal sphincter muscles. We conclude that both sexes have the ischiocavernosus muscles, $\mathrm{Mm}$. bulboesponjosos, $\mathrm{M}$. levator ani and external anal sphincter, and it is very important to study the perineal region of the animals, because understanding the function and location of each muscle we can contribute to future research on reproduction and animal behavior during copulation, helping to a better knowledge about reproductive potential of Erethizontidae rodents, and to contribute in the applied biotechnology development of reproduction, what can be helpful even in captivity reproduction of these animals besides the ones in free environment.
\end{abstract}

INDEX TERMS: Sexual dimorphism, perineum, Coendou prehensilis, prehensile-tailed porcupine, Rodent, hystricomorpha, perineal muscles.

RESUMO.- Coendou prehensilis é um mamífero da ordem Rodentia, que é composta por cinco subordens: Sciuromorfos, a qual pertencem os esquilos; Castorimorfos, onde

\footnotetext{
${ }^{1}$ Recebido em 5 de fevereiro de 2016.

Aceito para publicação em 27 de julho de 2016.

${ }^{2}$ Departamento de Cirurgia, Faculdade de Medicina Veterinária e Zootecnia (FMVZ), Universidade de São Paulo (USP), Av. Orlando Marques de Paiva 87, Bloco 17, Piso Superior, Cidade Universitária, São Paulo, São Paulo, SP 05508 270, Brasil. *Autor para correspondência: fcury@usp.br

${ }^{3}$ Departamento de Medicina Veterinária, Faculdade de Zootecnia e Engenharia de Alimentos (FZEA), USP, Av. Duque de Caxias Norte 225, Pirassununga, SP 13635-000, Brasil.
}

encontramos os castores; Myomorfos, a qual encontramos os ratos; Anomaluromorfos, Lebre-saltadora, e os Histricomorfos, onde observamos a capivara. Utilizamos nesta pesquisa o ouriço-cacheiro (Coendou prehensilis) sendo um macho e uma fêmea, ambos adultos. Estes animais foram encontrados em óbito por atropelamento nas rodovias da região de Pirassununga-SP e cedidos para o Laboratório de Anatomia do Departamento de Medicina Veterinária da Faculdade de Zootecnia e Engenharia de Alimentos da Universidade de São Paulo FZEA/USP devido a permissão do Ibama para estudar os animais (Registro SISBIO no. 
43274-1), os quais foram fixados com formaldeído a $10 \%$ e dissecados na região do períneo. Os resultados mostraram que a única característica que nos permite diferenciar machos de fêmeas, é o espaço entre o ânus e as genitais dos animais, sendo que o macho apresenta essa distância maior que a fêmea. 0 períneo é uma região extra cavitária de delimitação losangular, sendo essa delimitação feita pelos ossos interpubiano, púbico e pelos processos do púbis e ísquio. 0 períneo do Coendou prehensílis macho é composto por cinco principais músculos, sendo três encontrados dispostos no diafragma urogenital superficial, (Músculos isquiocavernosos, M. bulbocavernoso e Mm. Bulboesponjosos) e dois no diafragma pélvico (M. levantador do ânus e M. retrator do pênis). 0 períneo da fêmea é composto pelos músculos (isquiocavernoso, o bulboesponjoso, levantador do ânus e esfíncter anal externo). Conclui-se que ambos os sexos possuem os músculos isquiocavernosos, Mm. Bulboesponjosos, M. levantador do ânus e esfíncter anal externo, além de que o estudo da região perineal dos animais é de grande importância, pois através do entendimento da função e localização de cada músculo, podemos contribuir para futuras pesquisas sobre reprodução e comportamento animal durante a cópula auxiliando para um melhor entendimento do potencial reprodutivo de roedores da família Erethizontidae, além de contribuir na base do desenvolvimento da biotecnologia aplicada à reprodução visando até mesmo à reprodução desses animais em cativeiro além do meio ambiente livre.

TERMOS DE INDEXAÇÃO: Dimorfismo sexual, períneo, Coendou prehensilis, ouriço-cacheiro, roedor, histricomorfo, músculos perineais.

\section{INTRODUÇÃO}

Tratando-se de roedores, essa ordem (Rodentia), compõem $40 \%$ dos mamíferos existentes, sendo mais de 2000 espécies conhecidas atualmente. São encontrados praticamente no mundo todo, habitando florestas, cidades, ilhas, desertos, lagos, rios e ambientes de variadas temperaturas, exceto em oceanos e na Antártida. A diversidade de tamanho entre as espécies existentes varia de pequeno, médio e grande porte, podendo pesar de 7 gramas como Mus minutoides "rato-pigmeu-africano" a 70 quilos como Hydrochoerus hydrochoeris "capivara" (Carleton \& Musser 2005).

Coendou prehensilis, chamado popularmente de porco -espinho caixeiro ou ouriço-cacheiro, é um roedor pertencente a subordem Histricomorfa, sendo este, um herbívoro que vive em árvores de florestas tropicais desde o México até a América do sul, é um mamífero que pode pesar de 2 a $5 \mathrm{~kg}$ e medir de 30 a $60 \mathrm{~cm}$ de comprimento. Os nomes populares "porco-espinho" e "ouriço" foram dados devido o animal possuir o corpo coberto por espinhos curtos e extremamente pontiagudos sendo amarelados ou esbranquiçados, juntamente com o pelo, sendo sua arma contra predadores (Woods \& Kilpatrick 2005).

A classificação taxionomica de Coendou prehensilis, é descrita sendo do reino animalia, filo chordata, classe mammalia, ordem rodentia, subordem hystricomorpha, familia erethizontidae, subfamilia erethizontinae, gênero coendou e espécie C. Prehensilis Linnaeus, 1758.
Atualmente a morfologia de animais silvestres tem sido muito pesquisada, sendo o sistema reprodutor e região pélvica uma importante ferramenta nas pesquisas, pois o assoalho pélvico possui grande importância por contribuem no entendimento dos mecanismos relacionados à reprodução, ejaculação e processo de ereção, mantendo movimentos rítmicos durante toda a cópula, porém, poucos trabalhos descrevem sobre os aspectos específicos da anatomia na reprodução dos animais estudados, e sim sobre características gerais sobre o período reprodutivo e desenvolvimento embrionário comparativo (Franciolli et al. 2011, Pieri et al. 2012). Sendo assim, o estudo anatômico da musculatura nos permite de maneira geral identificar muitas características dos animais, como por exemplo, comportamento reprodutivo, hábitos alimentares devido sua movimentação e costumes devido certos músculos serem mais desenvolvidos (Aversi-Ferreira et al. 2006).

Gray et al. (1988) descreve o períneo como uma parte do tronco abaixo do diafragma pélvico em forma de losango, com a mesma limitação que a abertura da pelve. 0 corpo perineal é constituído de uma fibro musculatura que se encontra na porção mediana entre o canal e o diafragma urogenital, local onde se inserem músculos que se prendem ao corpo perineal. Gray define os músculos transversos superficiais e profundos do períneo como, Músculo bulboesponjoso, M. levantador do ânus, M. esfíncter anal externo e o músculo liso da túnica longitudinal do reto.

Watanabe Li-Sei (2000) descreve uma segunda porção de músculos perineais, sendo parte deles o diafragma urogenital localizado na parte anterior do períneo, possuindo tanto músculos superficiais quanto profundos, como o M. transverso superficial do períneo, $\mathrm{M}$. isquiocavernoso e $\mathrm{M}$. bulboesponjoso.

0 presente trabalho tem como principal objetivo descrever macroscopicamente a anatomia muscular perineal do Coendou prehensilis, a fim de avaliarmos sua importância e função na reprodução da espécie estudada, pois os dados apresentados poderão ser úteis para um melhor entendimento do potencial reprodutivo de roedores da família Erethizontidae, auxiliando na base do desenvolvimento da biotecnologia aplicada à reprodução visando até mesmo à reprodução desses animais em cativeiro além do meio ambiente livre e preservação tecidual.

\section{MATERIAL E MÉTODOS}

Para a execução da análise morfológica dos animais, foram utilizados dois Ouriços-cacheiros (um macho e uma fêmea), que vieram a óbito devido atropelamento. 0 presente trabalho possui permissão do SISBIO processo 43274-1 para ser realizado, além do consentimento da comissão de ética em pesquisa da Faculdade de Zootecnia e Engenharia de Alimentos FZEA/USP, processo 14.1.538.74.0. Os animais foram transportados para o Laboratório de anatomia animal no departamento de Medicina Veterinária da FZEA/USP. Após a fixação dos animais com formaldeído a 10\% e dissecção dos animais, os mesmos foram fotografados, conforme a dissecação avançava, para arquivamento dos resultados morfológicos obtidos.

A dissecação foi realizada utilizando-se apenas pinça e bisturi com o intuito de evidenciar todos os músculos da região perineal dos animais e descrever as características do dimorfismo sexual 
dos animais. As genitálias e os músculos do períneo de ambos foram fotografados na vista ventral e as genitais masculinas tanto em estado de relaxamento quanto contraído.

\section{RESULTADOS E DISCUSSÃO}

O períneo de Coendou prehensilis é delimitado na porção da pelve do animal, (diafragma da pelve), sendo esta região disposta de forma losangular (Fig.1A,B). Os ossos envolvidos na fixação dos músculos perineais são ossos interpúbico, ramos do ísquio, cóccix e tuberosidade isquiática, como descrito por Moore \& Dalley (1994) em períneo humano. Assim como na viscacha estudada por Pieri et al. 2012, a genitália externa se apresenta de maneira firme e sem modificações quanto à posição dos animais, sendo assim, quando assumem a postura quadrúpede a vulva e bolsa escrotal se mantém firmes (Fig.1A,B), diferente de alguns mamíferos como marsupiais e primatas, que po- dem apresentar uma disposição pendular quando estão na posição quadrúpede. 0 dimorfismo sexual da espécie é de difícil visualização, pois a coloração, tamanho e peso são semelhantes em ambos os sexos, o que não se pode afirmar que essa seja uma característica de histricomorfos no geral, pois o mesmo não ocorre na paca estudada por Borges et al. (2013), por exemplo, cuja bolsa escrotal se mostra bem mais aparente e de maior tamanho. Além disso, a dificuldade se dá também devido o macho não apresentar bolsa escrotal pendular, não possuindo tamanho consideravelmente visível para distinção dos sexos, sendo apenas um excesso de pele disposto na região perineal como uma vulva (Fig.1B e 2C). A difícil distinção dos sexos também se dá ao fato do pênis do animal manter-se completamente interno a cavidade pélvica, de modo não pendular com a glande completamente recoberta por um discreto prepúcio (Fig.2C).

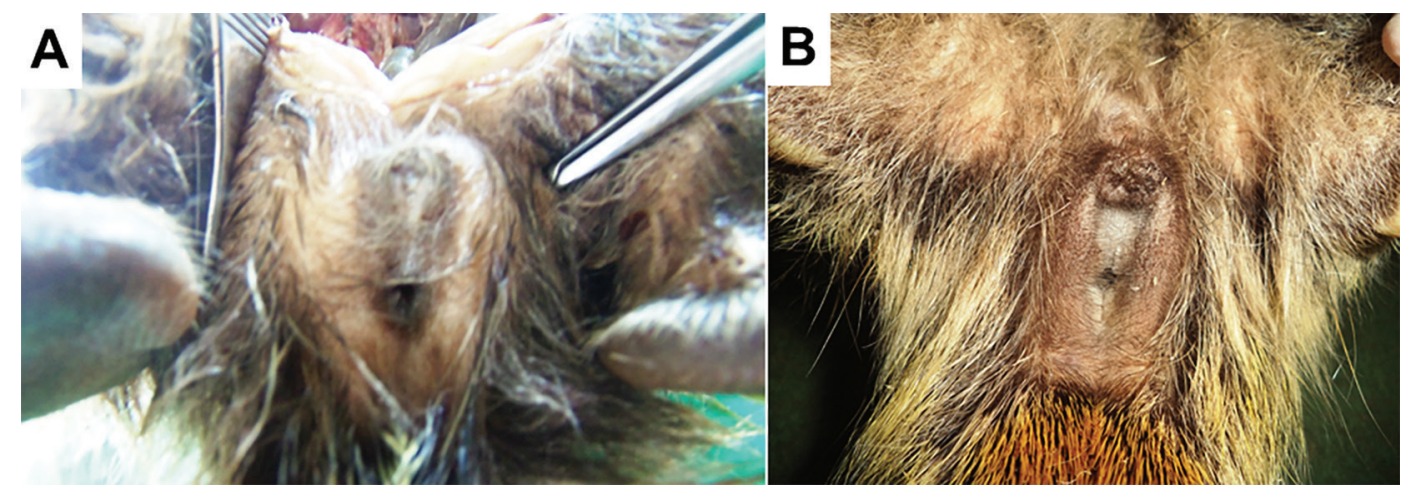

Fig.1. Vista ventral do períneo de Coendou prehensílis. (A) Região perineal da fêmea. (B) Região perineal do macho.

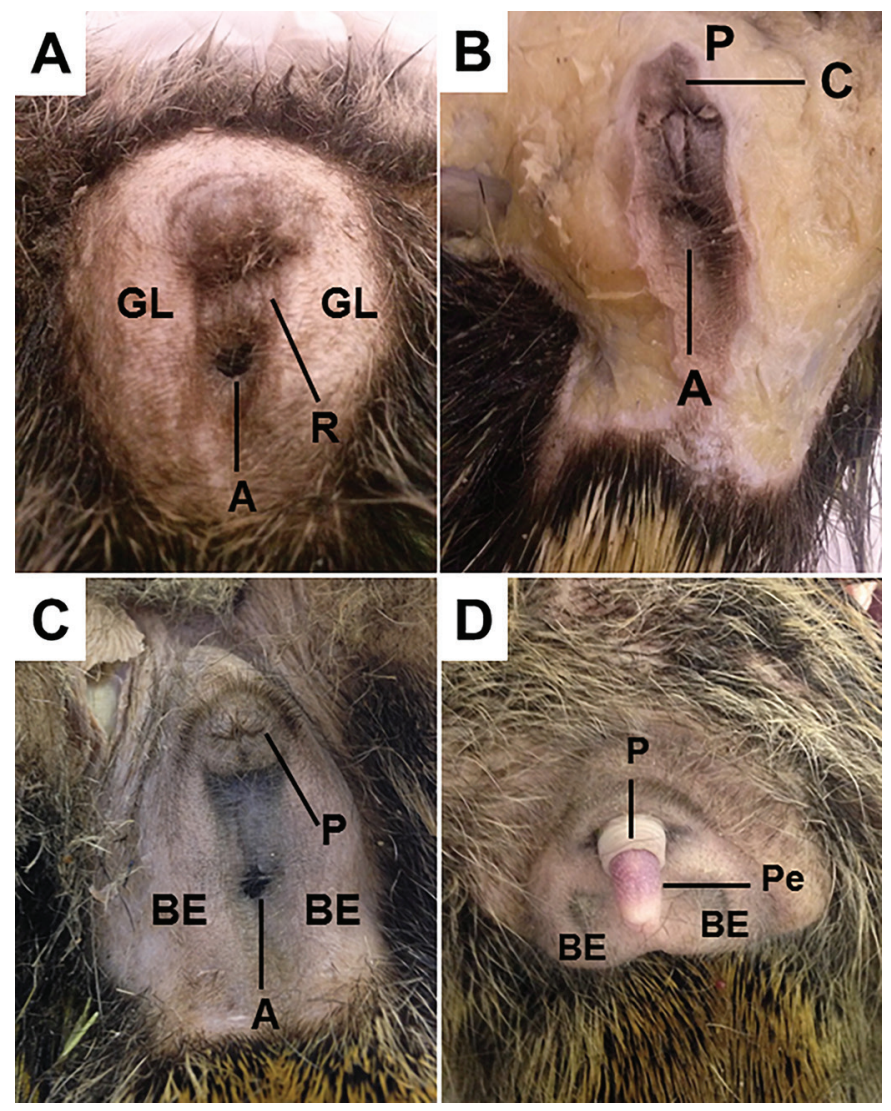

A curta rima está contida entre duas formações proeminentes e arredondadas, lateralmente dispostas, o que nas fêmeas representam os lábios maiores e nos machos o que seria uma bolsa escrotal (Fig.2A,C), semelhante a Galea spixii (Santos et al. 2015). Foram observadas diferenças na coloração do tegumento dos grandes lábios em relação à rima e da bolsa escrotal tanto antes quanto após a fixação. Na porção ventral da rima, atrás da comissura labial superior está situado o clitóris, sendo este discreto e não visível, mantendo-se dentro da comissura vulvar e recoberto totalmente por um pequeno prepúcio, o mesmo apresenta-se de coloração sem modificação aparente (Fig.2B). Na mesma localização presenciamos o prepúcio do macho, sendo este mais aparente (Fig.2C), se mostrando bem visível quando o pênis está exposto (Fig.2D).

Através da dissecação da linha média, evidenciamos a região perineal do Coendou prehensilis macho composta por cinco músculos, sendo que três encontram-se dispostos no

Fig.2. Vista ventral das genitais externas tricotomizadas (macho e fêmea) de Coendou prehensilis. (A) Observar na vulva a coloração do tegumento da rima (R), o clitóris (C), os grandes lábios (GL) e a abertura anal (A). (B) detalhe do clitóris (C) reduzido, observar a presença de um discreto prepúcio (P). (C) Genital do macho com pênis retraído, com o prepúcio (P) bem visível cerca de $1 \mathrm{~cm}$ acima do anus (A), ao redor um excesso de pele notório, que seria sua bolsa escrotal vazia (BE). (D) Genital do macho com pênis exposto (Pe), notar o prepúcio (P) na base do pênis. 

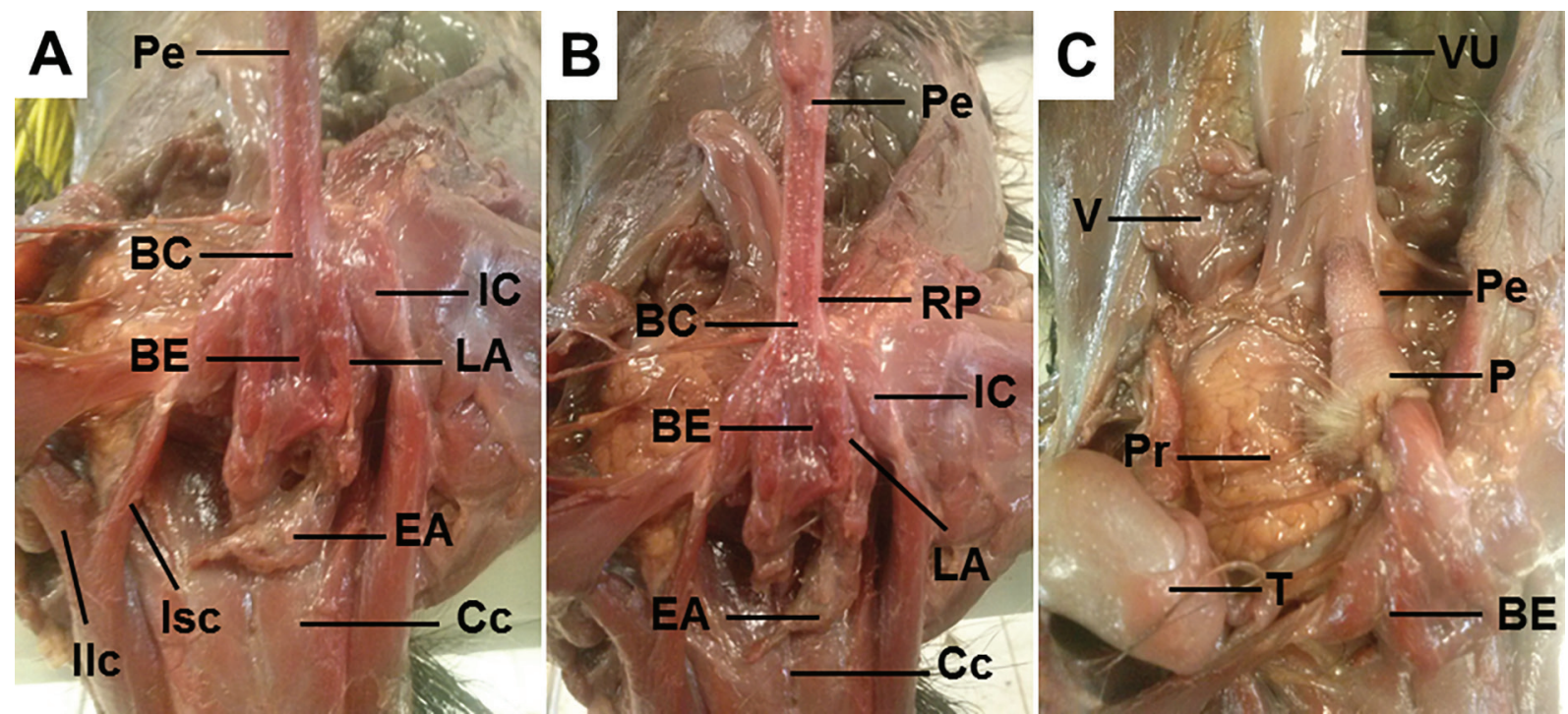

Fig.3. Região perineal de Coendou prehensílis macho (vista ventral). (A,B) Os músculos isquicavernoso (IC), bulboesponjoso (BE), levantador do ânus (LA), esfíncter anal (EA), retrator do pênis e Bulbocavernoso (BC) bem evidente na base do pênis (Pe), além dos músculos coccígeos (Cc), íliocaudal (Ilc) e ísquiocaudal (Isc). Em C: Visualização de órgãos como testículo (T), vesícula urinária (VU) e logo acima do músculo bulboesponjoso (BE), visualizamos o pênis (Pe) com o prepúcio (P), além de glândulas acessórias como próstata (Pr) e glândula vesicular (V).

diafragma urogenital superficial, composto pelo Músculo isquiocavernoso, bulbocavernoso e bulboesponjoso; bem como os músculos do diafragma pélvico, os quais destacamos o levantador do ânus e o retrator do pênis (Fig.3A,B).

Segundo Gray et al. (1988) e Moore \& Dalley (1994) a região perineal é formada pelo triângulo urogenital, sendo composta de camadas de fáscias: fáscia superficial do períneo, fáscia profunda do períneo fáscia inferior e superior do diafragma urogenital; tais estruturas estão fixadas lateralmente aos ramos do ísquio-púbico, enquanto que posteriormente fundem-se umas com as outras na borda posterior da região perineal. Em ambos os sexos, os músculos superficiais bulboespojosos e isquiocavernosos estão bem evidentes, fazendo parte da fáscia profunda do períneo, preenchendo e delimitando a região perineal, onde estão também as fáscias inferior e superior do diafragma urogenital além de estruturas como a raiz do pênis e as glândulas anexas bulbouretrais no caso do macho. (Fig.3A). Os músculos bulboespojosos, isquiocavernosos e retratores do pênis, estão localizados aderidos ao pênis e dispostos em pares, sendo que o M. bulboesponjoso se origina na porção cranial do bulbo e se insere na porção caudal da raiz do pênis (Fig.3A,B), semelhante à viscacha estudada por Pieri et al. (2012). De acordo com Sachs $(1982,1983)$ e Tang et al. (1998), a função desse músculo está ligada ao ato de ereção, respostas a estímulos na região genital e também auxilia, através de contrações, na expulsão de resquícios de urina e sêmen da uretra, assim como estudado por Bancila et al. (1999) em ratos.

Semelhante ao rato-topeira estudado por Seney et al. (2009) e a viscacha por Pieri et al. (2012), o M. isquiocavernoso de $C$. prehensílis se origina na tuberosidade do arco isquiático, inserindo-se na crura peniana. Nos machos possui função de auxiliar na ejaculação, contraindo os vasos dorsais do pênis, além de fixar os ramos do pênis à pelve, como uma ponte ligando um ao outro. Nas fêmeas de roedores como ratos e camundongos está ausente devido a diferente formação dos órgãos genitais (Jordan 1997, Poortmans \& Wyndaele 1998, Tullberg 1899).

$0 \mathrm{M}$. retrator do pênis se origina nas laterais do reto e segue ventral ao pênis desde a rafe mediana do períneo até inserir-se na flexura sigmoide (Fig.3C), resultado semelhante ao de Pieri et al. (2012) no estudo da viscacha e diferente do que descreve Martins (2003) na preguiça-de-coleira, cujo músculo retrator do pênis se origina no ramo ventral do osso púbico. Menezes et al. (2003), estudando a cutia, diz que este músculo é responsável pela ereção peniana, auxiliando na cópula, sendo assim denomina este músculo como subisquiocavernoso.

O M. levantador do ânus é disposto em par, se origina na sínfise púbica acima do reto em contato com a raiz do pênis, inserindo-se nas margens do esfíncter anal, formando um "V", exatamente como descrito por Pieri (2012) na viscacha (Fig.3A,B); sendo semelhante também ao homem, como relata Hall \& Brody (2001).

Dorsalmente ao ânus, podemos evidenciar o músculo coccígeo (Fig.3A,B), originando-se nas vertebras sacrais e seguindo ao longo da cauda do animal, assim como descreve Soares et al. (2014) no macaco-prego, possuindo também resultado semelhante no músculo íliocaudal, que se origina na sínfise púbica inserindo-se as primeiras vértebras caudais. Também é bem evidenciado o músculo isquiocaudal (Fig.3A,B), cujo tem mesma origem do músculo isquiocavernoso, e se insere nas primeiras vértebras caudais, diferente do descrito por Soares et al. 2014, pois no macaco-prego, cujo este músculo tem origem na espinha ilíaca póstero-inferior no sacro (Fig.3A,B).

$\mathrm{Na}$ fêmea de Coendou prehensilis, os resultados foram semelhantes ao macho quanto aos músculos isquiocaudal, coccígeo, esfíncter anal externo e ligamento anococcígeo 

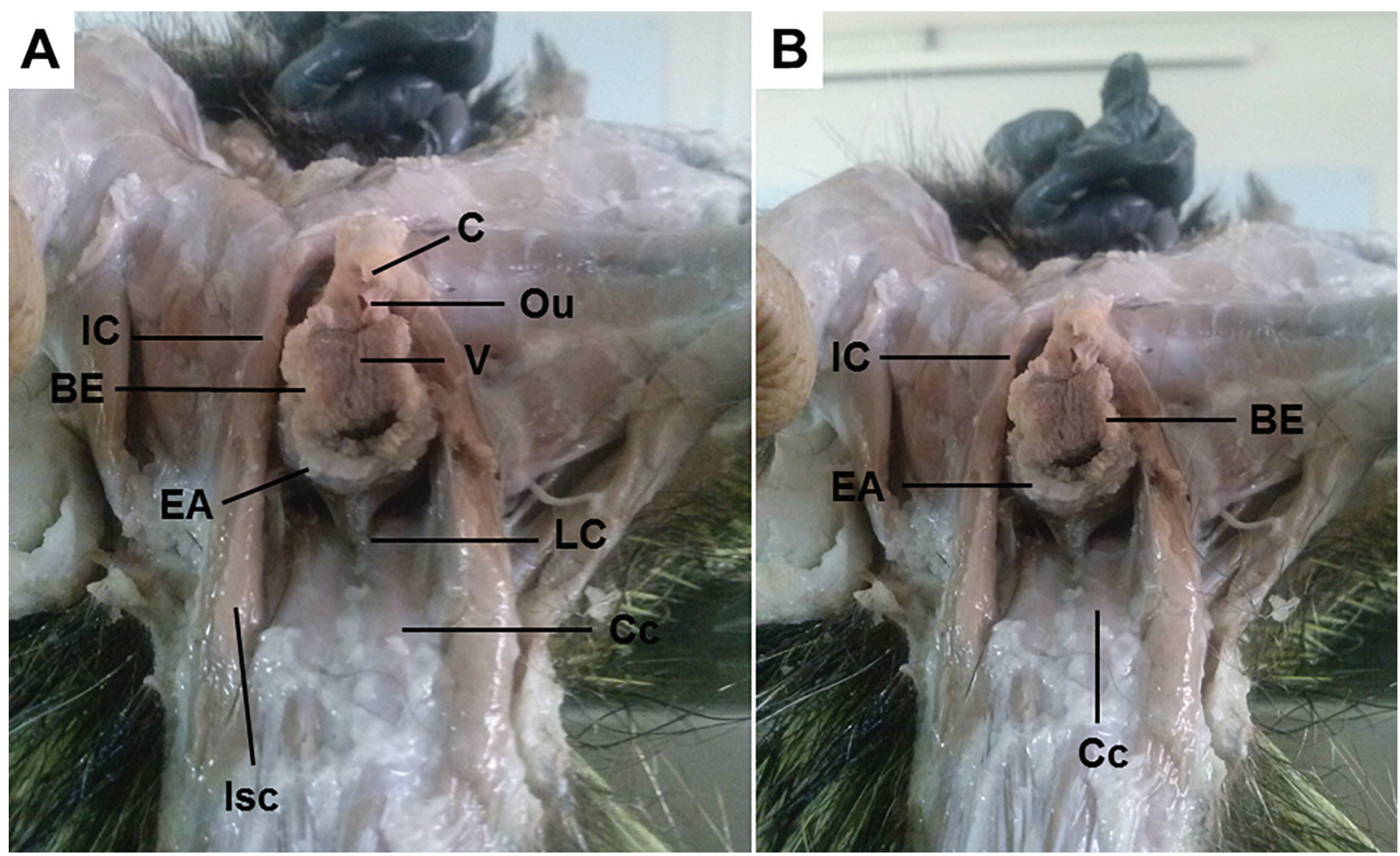

Fig.4. Região perineal de Coendou prehensílis fêmea (vista ventral). (A,B) Os evidenciamos os principais músculos do períneo, isquiocavernoso (IC), o bulboesponjoso (BE) e esfíncter anal externo (EA). Notar o clitóris (C) logo acima do óstio uretral externo (Ou), que desemboca a nível da vulva (V). 0 músculo coccígeo (Cc) possui ligação com o ânus através do ligamento anococcígeo (LC), possível também visualizar o $\mathrm{M}$. isquiocaudal (Isc).

(Fig.4A,B). 0 músculo bulboesponjoso circunda toda a região vulvar, envolvendo também o óstio uretral externo (Fig.4A,B). Por fim o músculo isquiocavernoso, semelhante ao macho da espécie, origina-se na tuberosidade do arco isquiático, porém possui um notável espaço maior de distância da genital comparada ao macho, devido não possuir a crura peniana (Fig.4B).

McKenna \& Nadelhaft (1986), Poortmans \& Wyndaele (1998) e Tullberg (1899) relatam que em fêmeas de outras espécies, como ratos e camundongos, o músculo isquiocavernoso está ausente ou pouco aparente, notando-se apenas um vestígio muscular, porém no rato-topeira africano está presente em ambos os sexos assim como nossos achados.

Em ratas, Bremer et al. (2003) revela que apresentam o músculo iliocaudal, cujo tem origem no íleo e se insere na quinta vertebra caudal, o músculo pubocaudal se originando no osso púbis e inserindo-se na terceira vertebra caudal e o músculo coccígeo que se origina no púbis e se insere na região da primeira vértebra caudal, quase semelhante ao Coendou prehensilis cujo origina-se nas vertebras sacrais e segue até o início da cauda do animal, assim como relatado por Soares et al. (2014) no macaco-prego.

Como descrito por Mayor et al. (2011), embora os histricomorfos apresentem uma grande diversidade tratando-se de costumes reprodutivos, a morfologia geral do sistema reprodutor dessa subordem é semelhante, como já descrito em várias fêmeas histricognatos presentes na América do sul, como o Erethizon sp. (Mossman \& Judas 1949), Lagidium sp. (Pearson 1949), Chinchilla laniger (Weir 1966),
Myoprocta pratti (Rowlands et al. 1970), Lagostomus maximus (Weir 1971), Myocastor coypus (Felipe et al. 1998) e Dasyprocta fuliginosa (Mayor et al. 2011), estando Coendou prehensilis entre eles.

Os resultados mostraram que a única característica que nos permite diferenciar machos de fêmeas, é o espaço entre o ânus e as genitais dos animais, sendo que o macho apresenta essa distância maior que a fêmea (Fig.1).

De acordo com o trabalho, concluímos que é de grande importância o estudo da região perineal dos animais, pois através do entendimento da função e localização de cada músculo, podemos contribuir para futuras pesquisas sobre reprodução e comportamento animal durante a cópula.

Agradecimentos.- À FAPESP pelo apoio financeiro (Processo número: 2013/05839-9), ao Departamento de Medicina Veterinária da Faculdade de Zootecnia e Engenharia de Alimentos FZEA/USP pelas instalações para o desenvolvimento da pesquisa e ao SISBIO pela permissão concedida para trabalhar com a espécie.

\section{REFERÊNCIAS}

Aversi-Ferreira T.A., Vieira L.G., Pires R.M. \& Silva Z. \& Penhasilva N. 2006. Estudo anatômico dos músculos flexores superficiais do antebraço no macaco Cebus apella. Bioscience J. 22:139-144.

Bancila M., Verge D., Rampin O., Backstrom J.R., Sanders-Bush E., McKenna K., Marson L., Calas A. \& Giuliano F. 1999. 5-hydroxytryptamine 2c receptors on spinal neurons controlling penile erection in the rat. Neuroscience 92:1523-1537.

Borges E.M., Branco E., Lima A.R., Leal L.M., Martins L.L., Reis A.C.G., Cruz C., Machado M.R.F. \& Miglino M.A. 2013. Morfologia e topografia dos órgãos genitais masculinos externos da paca (Cuniculus paca Linnaeus, 1766). Biotemas 26(4):209-220. 
Bremer R.E., Barber M.D, Coates K.W., Dolber P.C. \& Thor K.B. 2003. Innervation of the levator ani and coccygeus muscles of the female rat. Anat. Rec. 275A:1031-1041.

Carleton M.D. \& Musser G.G. 2005. Order Rodentia, p.745-752. In: Wilson D.E. \& Reeder D.M. (Eds), Mammalian Species of the World. Vol.2. 3rd ed. Johns Hopkins University Press, Baltimore.

Felipe A., Calleja J. \& Cabodevila J. 1998. Anatomicohistological characteristics of female genital tubular organs of the South American nutria (Myocastor coypus). Anat. Histol. Embryol. 27:245-250.

Franciolli A.L.R., Ambrósio C.E., Oliveira M.F., Morini A.C., Favaron P.O., Machado M.R.F. \& Miglino M.A. 2011. Os histricomorfos sul-americanos: uma análise comparativa do desenvolvimento embriológico. Pesq. Vet. Bras. 31:441-446.

Gray D., Gardner E. \& O'rahilly R. 1988. Anatomia: estudo regional do corpo humano. $3^{\underline{a}}$ ed. Guanabara Koogan, Rio de Janeiro. 815p.

Hall C.E. \& Brody L.T. 2001. Exercício terapêutico: na busca da função. Guanabara Koogan, Rio de Janeiro. 107p.

Jordan C. 1997. Androgen receptor (Ar) immunoreactivity in rat pudendal motoneurons: implications for accessory proteins. Horm. Behav. 32:1-10.

Linnaeus C. 1758. Tomus I. Syst. Nat., ed. 10. Holmiae, Laurentii Salvii (1/4):1-824.

Martins D.S. 2003. Morfologia do sistema reprodutor masculino da preguiça-de-coleira (Bradypus torquatus Illiger, 1811). Dissertação de Mestrado no Pograma de Pós-Graduação em Animais Domésticos e Silvestres, Faculdade de Medicina Veterinária e Zootecnia, Universidade de São Paulo, São Paulo. 116p.

Mayor P., Bodmer R.E. \& Lopez-Bejar M. 2011. Functional anatomy of the female genital organs of the wild black agouti (Dasyprocta fuliginosa) female in the Peruvian Amazon. Anim. Reprod. Sci. 123:249-257.

McKenna K.E. \& Nadelhaft I. 1986. The organization of the pudendal nerve in the male and female rat. J. Comp. Neurol. 248:532-549.

Menezes A.J.D., Carvalho M.A.M., Assis Neto C.A., Oliveira F.M., Farias C.E., Miglino M.A. \& Medeiros X.G. 2003. Morfologia dos órgãos genitais externos do macho de cutia (Dasyprocta aguti Linneus, 1766). Braz. J. Vet. Res. Anim. Sci. 40:148-153.

Moore K.L. \& Dalley A.F. 1994. Anatomia: orientando para a clínica. 3ª ed. Guanabara Koogan, Rio de Janeiro. 1142p.

Mossman H.W. \& Judas I. 1949. Accessory corpora lutea, lutein cell origin and the ovarian cycle in the Canadian porcupine. Am. J. Anat. 85:1-39.

Pearson O.P. 1949. Reproduction of a South American rodent, the mountain viscacha. Am. J. Anat. 84:143-174.
Pieri N.C.G., Flamini A.M., Barbeito C.G., Casals J.B., Roque B.K., Favaron P.O., Miglino M.A. \& Martins D.S. 2012. Forma e função dos músculos perineais da viscacha (Lagostomus maximus). Pesq. Vet. Bras. 32(2):183187.

Poortmans A. \& Wyndaele J.J.M. 1998. Levator ani in the rat: does it really lift the anus. Anat. Rec. 251:20-27.

Rowlands I.W., Tam W.H. \& Kleiman D.G. 1970. Histological and Biochemichal Studies on the ovary and of progesterone levels in the systemic blood of the green acouchi (Myoprocta pratti). J. Reprod. Fertil. 22:533545.

Sachs B.D. 1982. Role of striated penile muscles in penile relexes, copulation and induction of pregnancy in the rat. J. Reprod. Fertil. 66:433443.

Sachs B.D. 1983. Potency and fertility: hormonal and mechanical causes and effects of penile actions in rats, p.86-110. In: Balthazart J., Prve E. \& Gilles R. (Eds), Hormones and Behaviour in Higher Vertebrates. Springer-Verlag, Berlin.

Santos A.C., Viana D.C., Bertassoli B.M., Oliveira G.B., Oliveira D.M., Bezerra F.V.F., Oliveira M.F. \& Assis-Neto A.C. 2015. Caracterização do ciclo estral de Galea spixii (Wagler, 1831). Pesq. Vet. Bras. 35(1):89-94.

Seney M.L., Kelly D.A., Bruce D. Goldman B.D., Umbera R.S. \& Forger N.G. 2009. Social structure predicts genital morphology in African mole-rats. PLOS ONE 4:74-77.

Soares N.P., Vieira V.S., Carneiro-e-Silva F.O., Lima F.C., Araújo E.G. \& Pereira K.F. 2014. Músculos da região perineal do macaco-prego (Sapajus libidinosus). Arqs Mudi, Maringá, 18(3):39-48.

Tang Y., Rampin O., Calas A., Facchinetti P. \& Giuliano F. 1998. Oxytocinergic and serotonergic innervation of identified lumbosacral nuclei controlling penile erection in the male rat. Neuroscience 82:241-254.

Tullberg T. 1899. Über das System der Nagethiere: eine phylogenetische Studie. Nov. Acta Reg. Soc. Sci., Uppsala, 3:1-514.

Watanabe Li-Sei 2000. Erhart: Elementos de Anatomia Humana. 9a ed. Atheneu, São Paulo. 243p.

Weir B.J. 1966. Aspects of reproduction in chinchilla. J. Reprod. Fertil. 12:410-411.

Weir B.J. 1971. The reproductive organs of the female plains viscacha, $L a$ gostomus maximus. J. Reprod. Fertil. 25:365-373.

Woods C.A. \& KIlpatrick C.W. 2005. Infraorder hystricognathi, p.15381600. In: Wilson D.E. \& Reeder D.M. (Eds), Mammalian Species of the World: a taxonomic and geographic reference. Vol.2. 3rd ed. John Hopkins University Press, Baltimore. 